\title{
Genetic correlations between conformation traits and radiographic findings in the limbs of German Warmblood riding horses
}

\author{
Kathrin Friederike STOCK*, Ottmar DISTL \\ Department of Animal Breeding and Genetics, University of Veterinary Medicine Hannover \\ (Foundation), Bünteweg 17p, 30559 Hannover, Germany
}

(Received 22 March 2006; accepted 7 June 2006)

\begin{abstract}
Studbook inspection (SBI) data of 20768 German Warmblood mares and radiography results (RR) data of 5102 Hanoverian Warmblood horses were used for genetic correlation analyses. The scores on a scale from 0 to 10 were given for conformation and basic quality of gaits, resulting in 14 SBI traits which were used for the correlation analyses. The radiographic findings considered included osseous fragments in fetlock (OFF) and hock joints $(\mathrm{OFH})$, deforming arthropathy in hock joints (DAH) and distinct radiographic findings in the navicular bones (DNB) which were analyzed as binary traits, and radiographic appearance of the navicular bones (RNB) which was analyzed as a quasi-linear trait. Genetic parameters were estimated multivariately in linear animal models with REML using information on 24448 horses with SBI and/or RR records. The ranges of heritability estimates were $\mathrm{h}^{2}=0.14-0.34$ for the RR traits and $\mathrm{h}^{2}=0.09-0.50$ for the SBI traits. Negative additive genetic correlations of $r_{\mathrm{g}}=-0.19$ to -0.56 were estimated between OFF and conformation of front and hind limbs and walk at hand, and between DNB and hind limb conformation. There were indications of negative additive genetic correlations between DAH and all SBI traits, but because of low prevalence and low heritability of DAH, these results require further scrutiny. Positive additive genetic correlations of $r_{g}=0.37-0.52$ were estimated between OFF and withers height and between OFH and withers height, indicating that selection for taller horses will increase disposition to develop OFF and OFH. Selection of broodmares with regards to functional conformation will assist, but cannot replace possible selection against radiographic findings in the limbs of young Warmblood riding horses, particularly with regards to OFF.
\end{abstract}

riding horse / conformation / studbook inspection / radiographic finding / additive genetic correlation

\section{INTRODUCTION}

Conformation, performance and health are important criteria for selection of Warmblood horses. Breeding aims of most modern Warmblood horse

\footnotetext{
*Corresponding author: Kathrin-Friederike.Stock@ tiho-hannover.de
} 
breeds are focused on performance, particularly on performance in riding sports [17]. Several, but not all genetic studies on this topic have shown the relation between particular conformation traits and performance in equestrian sports $[11,12,21,22]$. Evaluation of and selection for functional conformation is therefore used as a tool for indirect performance selection. Furthermore, positive effects on longevity of riding horses have been determined for favorable total conformation and leg conformation [44]. Particular conformation faults are known to predispose horses to orthopedic problems because they lead to abnormal distribution of load and wear [1, 10, 21, 26, 28, 30,33]. Some relation between conformation traits and soundness has been identified in Standardbred trotters [21] and Warmblood riding horses [11], and favorable orthopedic status, as measured by palpation of legs and results of flexion tests at 4 years of age, was found to lower the risk of Swedish Warmblood riding horses to be culled [44]. Relationships between conformation and radiographic appearance of parts of the equine skeleton are likely, but have rarely been studied yet in the Warmblood horse. Therefore the aim of this study was to determine the genetic correlations between prevalent radiographic findings in the limbs of young Warmblood riding horses and conformation criteria routinely evaluated on the occasion of studbook inspection in the same breed.

\section{MATERIALS AND METHODS}

\subsubsection{Radiographic data}

The results of radiographic examinations of 5102 Hanoverian Warmblood horses, which were preliminarily appointed for sale at riding horse auctions of the Association of Hanoverian Warmblood breeders (Verband hannoverscher Warmblutzüchter e.V., VHW) between 1997 and 2004, were available for the present study. More than 99\% of these horses were born from 1992 to 2001.

Radiographic examination of all horses included at least ten standard projections of their limbs. Detailed description of the examination and documentation procedure is given elsewhere [37,39-42]. Osseous fragments in fetlock (OFF) and hock joints (OFH), deforming arthropathy in hock joints (DAH), radiographic appearance of the navicular bones (RNB) and distinct radiographic findings in the navicular bones (DNB) were the quantitatively most important radiological traits and were therefore included in this study. Binary coding was used for OFF, OFH, DAH and DNB with 1 denoting presence and 0 denoting absence of the respective radiographic finding. RNB was defined as a quasilinear trait with 8 categories from 0 (absence of any abnormal radiographic 
findings) to 7 reflecting increasing extent and/or prominence of radiographic findings in the navicular bones of the front feet [37]. DNB was derived from RNB such that horses of RNB categories 0 and 1 were considered unaffected by DNB, and horses of RNB categories 2 to 8 were considered affected by DNB.

\subsubsection{Conformation data}

Conformation data were taken from a dataset comprising evaluation results from studbook inspections of the VHW from 1979 to 2004. The information referred to 65246 German Warmblood mares. For this study, only information on contemporaries of the radiographed horses, i.e. on mares born between 1992 and 2001, was considered. These 20768 mares were presented for VHW studbook registration in 1995 to 2004 at a mean age of 3.5 years (range 3 to 6 years). The number of mares judged per year ranged between 1191 and 2354 (mean 2076.8), and the number of mares judged per date (day, month, year) and place ranged between 1 and 135 (mean 21.82).

Following the measurement of withers height (WH), the mares were judged with regards to conformation and basic quality of gaits. Judgment of conformation included conformation of the head (Head), neck (Neck) and saddle bearing area (Sad), conformation of front limbs (ConFL) and hind limbs (ConHL), type (Type), frame (Frame), and general impression and development (Dev). Judgment of gaits included walk at hand (WalkH), correctness of gaits (Corr) in walk and trot at hand, and impetus and elasticity (Imp) in trot at hand. Scores on a scale from 0 to 10 were allocated to each of these traits, with 0 denoting not shown or not evaluable, 1 denoting unsatisfactorily shown and 10 denoting excellently shown. A score for total conformation (ConT) was calculated as a weighted average of the six individual scores for Frame, Head, Neck, Sad, ConFL and ConHL. A total score (Tot) was calculated as the mean of ConT and the individual scores for Type, Corr, Imp, WalkH, and Dev. Completeness of SBI data was larger than $99 \%$ for base information and all traits in the 20768 evaluated mares.

\subsubsection{Combination of conformation and radiographic data}

The correlation analyses included in total 24448 German Warmblood horses for which SBI and/or radiographic data (radiography results, RR) were avail-

able. SBI and RR records were available for 1422 horses, only SBI records for 19346 horses, and only RR records for 3680 horses. 


\subsubsection{Pedigree data}

Pedigree information of all horses was provided by a unified animal ownership database (Vereinigte Informationssysteme Tierhaltung w.V.) in Verden on the Aller, Germany. For the genetic analyses, three ancestral generations of all horses with SBI and/or RR data were considered. The relationship matrix comprised in total 63532 horses, including 7743 base animals. The average number of offspring was 19.68 (range 1-930) per sire $(\mathrm{n}=1242)$, and 14.12 (range 1-398) per maternal grandsire $(n=1724)$. More than $99 \%$ of sires and maternal grandsires had offspring in SBI and RR data, and 586 stallions occurred as both sires and maternal grandsires in the data.

\subsection{Basic statistical analyses}

Statistical analyses included the 5 RR traits OFF, OFH, DAH, DNB and RNB, and 14 SBI traits, i.e. Head, Neck, Sad, ConFL, ConHL, ConT, Type, Frame, Dev, WalkH, Corr, Imp, Tot, and WH.

\subsection{Genetic analyses}

Genetic parameters were estimated multivariately in linear animal models with Residual Maximum Likelihood (REML) using VCE-5, Version 5.1.2 (Variance Component Estimation) [18]. Models for the genetic analyses were developed on the basis of the results of significance tests and model fit test statistics of analyses of variance. SBI traits and RNB were analyzed in general and mixed linear models using the GLM and MIXED procedures, and OFF, $\mathrm{OFH}, \mathrm{DAH}$ and DNB were analyzed in generalized linear models with binomial distribution and probit link function, using the procedure GENMOD of SAS ${ }^{\circledR}$, version 9.1.3 (SAS ${ }^{\circledR}$ Institute, Cary, NC, USA, 2005). The model for the SBI traits included age at SBI evaluation as the fixed effect and combined year-place effect as the random effect, and the model for the RR traits included designated auction (OFF) or designated auction, season of birth and interaction between sex and examination age (OFH, DAH, DNB, RNB) as fixed effects.

$$
\begin{aligned}
\mathrm{y}_{\mathrm{ijkpq}} & =\mu+\mathrm{AGE}_{\mathrm{SBIi}}+\text { place }_{\mathrm{SBI}} \times \mathrm{year}_{\mathrm{SBIjk}}+\mathrm{a}_{\mathrm{p}}+\mathrm{e}_{\mathrm{ijkpq}} \\
\mathrm{y}_{\mathrm{lpq}} & =\mu+\mathrm{AUCT}_{1}+\mathrm{a}_{\mathrm{q}}+\mathrm{e}_{\mathrm{lpq}} \\
\mathrm{y}_{\mathrm{lmnopq}} & =\mu+\mathrm{AUCT}_{1}+\mathrm{SEX} \times \mathrm{AGE}_{\mathrm{RRmn}}+\mathrm{BIRTH}_{\mathrm{o}}+\mathrm{a}_{\mathrm{p}}+\mathrm{e}_{\mathrm{lmnopq}}
\end{aligned}
$$

with $\mathrm{y}_{\ldots \mathrm{pq}}=\mathrm{SBI}$ score or $\mathrm{WH}$ or radiographic finding of the individual horse, $\mu=$ model constant, $\mathrm{AGE}_{\mathrm{SBI}}=$ age at $\mathrm{SBI}$ evaluation $(\mathrm{i}=1-3 ; 3$ years, 
4 years, $\geq 5$ years of age), place $_{\mathrm{SBI}} \times$ year $_{\mathrm{SBI} j \mathrm{j}}=$ random effect of interaction between place $(\mathrm{j}=1-121)$ and year of SBI evaluation $(\mathrm{k}=1-10 ; 1994 / 1995$, $1996, \ldots, 2004)$, AUCT $_{1}=$ fixed effect of designated auction $(1=1-48)$, $\mathrm{SEX} \times \mathrm{AGE}_{\mathrm{RR} m n}=$ fixed effect of interaction between sex $(\mathrm{m}=1-3)$ and age at radiographic examination $(n=1-4 ; 3$ years, 4 years, 5 years, 6 years of age), BIRTH $_{0}=$ fixed effect of season of birth (o $=1-3$; November through March, April, May through October), $a_{p}=$ random additive genetic effect of the individual horse $(\mathrm{p}=1-63532)$, and $\mathrm{e}_{\ldots \mathrm{q}}=$ random residual.

Bivariate analyses of all possible combinations of RR and SBI traits were performed in order to obtain variance and covariance estimates. Heritabilities $\left(\mathrm{h}^{2}\right)$, additive genetic $\left(\mathrm{r}_{\mathrm{g}}\right)$, residual $\left(\mathrm{r}_{\mathrm{e}}\right)$ and phenotypic correlations $\left(\mathrm{r}_{\mathrm{p}}\right)$ were calculated from estimated additive genetic and residual (co)variances. Heritability and residual correlation estimates of binary traits (OFF, OFH, DAH, DNB) were transformed from the observed scale to the underlying liability scale $[6,43]$. Efficiency of transformation factors with encountered data structures has been proven previously [42].

Because differences between corresponding heritability estimates for each of the RR and SBI traits were negligibly small $(\leq 0.01)$, only mean heritabilities $\left(\mathrm{h}^{2}\right)$ and mean standard errors of heritabilities $\left(\mathrm{SE}_{\mathrm{h}^{2}}\right)$ will be reported.

\section{RESULTS}

\subsection{Basic statistical analyses}

Means and ranges of SBI scores and withers height in the 20768 evaluated mares are shown in Table I. Mean SBI scores ranged between 6.35 (ConHL) and 7.23 (Head), range of SBI scores from 4.0 to 9.0 (ConT, Corr, Tot) to 3.0 to 10.0 (Neck, Imp). Average WH was $165 \mathrm{~cm}$. Details on the distribution of SBI scores are given in a supplementary table available at www.edpsciences.org.

Prevalences of radiographic findings in the 5102 radiographed horses were $27.91 \%$ for OFF, $9.25 \%$ for OFH, $7.66 \%$ for DAH, and $20.13 \%$ for DNB. Mean RNB score was 0.69 .

\subsection{Genetic analyses}

For the SBI traits, heritability estimates and their standard errors are given in Table I. Heritability estimates for the SBI scores ranged between $\mathrm{h}^{2}=0.09$ $(\mathrm{ConFL})$ and $\mathrm{h}^{2}=0.50(\mathrm{Head})$ with standard errors of $\mathrm{SE}_{\mathrm{h}^{2}}=0.01-0.02$. Heritability estimates for $\mathrm{WH}$ was $\mathrm{h}^{2}=0.50\left(\mathrm{SE}_{\mathrm{h}^{2}}=0.02\right)$. 
Table I. Mean scores and ranges of scores on a scale from 0 (not shown) to 10 (excellently shown) of conformation traits and means and ranges of height at withers in 20768 mares evaluated on the occasion of studbook inspection (SBI) of the Hanoverian Warmblood horses in 1995-2004, with corresponding heritability estimates $\left(\mathrm{h}^{2}\right)$ and their standard errors $\left(\mathrm{SE}_{\mathrm{h}^{2}}\right)$.

\begin{tabular}{lcc}
\hline Trait & Mean (range) & $\mathrm{h}^{2} \pm \mathrm{SE}_{\mathrm{h}^{2}}$ \\
\hline Type & $7.06(4-10)$ & $0.381 \pm 0.014$ \\
Head & $7.23(4-10)$ & $0.496 \pm 0.015$ \\
Neck & $7.01(3-10)$ & $0.313 \pm 0.014$ \\
Saddle bearing area & $7.00(4-10)$ & $0.297 \pm 0.013$ \\
Frame & $6.79(3-9)$ & $0.192 \pm 0.012$ \\
Total conformation & $6.78(4-9)$ & $0.231 \pm 0.013$ \\
Front limb conformation & $6.62(3-9)$ & $0.090 \pm 0.008$ \\
Hind limb conformation & $6.35(3-9)$ & $0.107 \pm 0.009$ \\
General impression and development & $6.81(4-10)$ & $0.263 \pm 0.013$ \\
Correctness of gaits & $6.69(4-9)$ & $0.115 \pm 0.010$ \\
Walk at hand & $6.84(4-10)$ & $0.260 \pm 0.013$ \\
Impetus and elasticity & $6.93(3-10)$ & $0.363 \pm 0.014$ \\
Total score & $6.87(4-9)$ & $0.317 \pm 0.014$ \\
Height at withers & $165.44(143-185)$ & $0.487 \pm 0.019$ \\
\hline
\end{tabular}

For the binary RR traits, heritability estimates were $\mathrm{h}^{2}=0.08$ for OFF, $\mathrm{h}^{2}=$ 0.11 for $\mathrm{OFH}, \mathrm{h}^{2}=0.05$ for DAH, and $\mathrm{h}^{2}=0.11$ for DNB $\left(\mathrm{SE}_{\mathrm{h}^{2}}=0.01-0.02\right)$ before transformation, and $\mathrm{h}^{2}=0.14$ for $\mathrm{OFF}, \mathrm{h}^{2}=0.34$ for $\mathrm{OFH}, \mathrm{h}^{2}=0.17$ for DAH, and $\mathrm{h}^{2}=0.22$ for DNB $\left(\mathrm{SE}_{\mathrm{h}^{2}}=0.03-0.06\right)$ after transformation. The heritability estimate of RNB was estimated $a \mathrm{~h}^{2}=0.15\left(\mathrm{SE}_{\mathrm{h}^{2}}=0.02\right)$.

Additive genetic correlations estimated between SBI and RR traits are given in Table II. Negative additive genetic correlations in the range of $r_{g}=-0.15$ to $r_{g}=-0.56$ were estimated between OFF and ConFL, ConHL and WalkH, between $\mathrm{OFH}$ and Head and Imp, between DAH and all SBI traits, between $\mathrm{DNB}$ and ConHL, and between RNB and ConHL ( $\left.\mathrm{SE}_{\mathrm{rg}} \leq 0.12\right)$. Positive additive genetic correlations in the range of $r_{g}=0.15$ to $r_{g}=0.52$ were estimated between OFF and Head, Neck and WH, between OFH and WH, between DNB and Corr, and between RNB and Corr, WalkH and Imp ( $\left.\mathrm{SE}_{\mathrm{rg}}=0.07-0.10\right)$.

\section{DISCUSSION}

The aim of this study was to investigate the genetic correlations between prevalent radiographic findings in the limbs of young Warmblood riding horses, and conformation parameters which are routinely evaluated on large numbers of potential Warmblood broodmares. 
Table II. Additive genetic correlations with their standard errors between prevalent radiographic findings in the limbs of 5102 radiographed Hanoverian Warmblood horses and conformation traits in 20678 mares evaluated on the occasion of studbook inspection (SBI) of the Hanoverian Warmblood horses in 1995-2004.

\begin{tabular}{|c|c|c|c|c|c|}
\hline SBI & OFF & $\mathrm{OFH}$ & DAH & DNB & RNB \\
\hline Type & $0.078 \pm 0.089$ & $-0.068 \pm 0.083$ & $-0.338 \pm 0.104$ & $0.018 \pm 0.077$ & $0.040 \pm 0.070$ \\
\hline Head & $0.226 \pm 0.088$ & $-0.162 \pm 0.071$ & $-0.167 \pm 0.113$ & $0.028 \pm 0.073$ & $0.019 \pm 0.066$ \\
\hline Neck & $0.172 \pm 0.084$ & $-0.063 \pm 0.013$ & $-0.187 \pm 0.103$ & $0.032 \pm 0.076$ & $0.061 \pm 0.073$ \\
\hline $\mathrm{Sad}$ & $0.107 \pm 0.089$ & $0.136 \pm 0.073$ & $-0.187 \pm 0.097$ & $-0.086 \pm 0.077$ & $-0.047 \pm 0.070$ \\
\hline Frame & $0.003 \pm 0.097$ & $0.099 \pm 0.085$ & $-0.352 \pm 0.106$ & $-0.130 \pm 0.020$ & $0.069 \pm 0.076$ \\
\hline ConT & $-0.004 \pm 0.096$ & $-0.030 \pm 0.089$ & $-0.513 \pm 0.105$ & $-0.100 \pm 0.086$ & $-0.073 \pm 0.082$ \\
\hline ConFL & $-0.288 \pm 0.102$ & $-0.073 \pm 0.030$ & $-0.308 \pm 0.110$ & $0.012 \pm 0.092$ & $-0.021 \pm 0.088$ \\
\hline ConHL & $-0.276 \pm 0.104$ & $0.025 \pm 0.097$ & $-0.561 \pm 0.115$ & $-0.148 \pm 0.096$ & $-0.098 \pm 0.092$ \\
\hline Dev & $0.074 \pm 0.087$ & $-0.127 \pm 0.018$ & $-0.441 \pm 0.112$ & $0.074 \pm 0.088$ & $0.124 \pm 0.076$ \\
\hline Corr & $-0.056 \pm 0.018$ & $-0.035 \pm 0.091$ & $-0.336 \pm 0.110$ & $0.154 \pm 0.090$ & $0.196 \pm 0.085$ \\
\hline WalkH & $-0.160 \pm 0.081$ & $0.015 \pm 0.0^{7}$ & $-0.168 \pm 0.099$ & $0.120 \pm 0.075$ & $0.146 \pm 0.070$ \\
\hline $\operatorname{Imp}$ & $-0.084 \pm 0.078$ & $-0.164 \pm 0.004$ & $-0.250 \pm 0.108$ & $0.117 \pm 0.072$ & $0.206 \pm 0.067$ \\
\hline Tot & $0.041 \pm 0.009$ & $-0.134 \pm 0.017$ & $-0.424 \pm 0.104$ & $0.095 \pm 0.081$ & $0.138 \pm 0.074$ \\
\hline WH & $0.374 \pm 0.101$ & $0.517 \pm 0.077$ & $-0.185 \pm 0.141$ & $-0.115 \pm 0.084$ & $-0.035 \pm 0.082$ \\
\hline
\end{tabular}

Sad: saddle bearing area; ConT: total conformation; ConFL: front limb conformation; ConHL: hind limb conformation; Dev: general impression and development; Corr: correctness of gaits; WalkH: walk at hand; Imp: impetus and elasticity; Tot: total score; WH: height at withers; OFF: osseous fragments in fetlock joints (binary); OFH: osseous fragments in hock joints (binary); DAH: deforming arthropathy in hock joints (binary); DNB: distinct radiographic findings in the navicular bones (binary); RNB: radiographic appearance of the navicular bones (quasi-linear).

Radiographic data were taken from standardized pre-sale veterinary medical examinations, which were performed on all horses preliminarily appointed for sale at riding horse auctions of the VHW. Osseous fragments in fetlock $(\mathrm{OFF})$ and hock joints (OFH), deforming arthropathy in hock joints (DAH) and radiographic changes in the navicular bones (DNB, RNB) were included in this study, because they were previously identified as the most prevalent in the limbs of young Warmblood riding horses [39-41]. Prevalences of radiographic findings were also determined in young horses preliminarily appointed for auction sale and may be even higher in the whole population of the Hanoverian Warmblood horse. Quasi-linear trait definition was recently found to be preferable for genetic analysis of radiographic findings in the navicular bones [37], but additional use of commonly used binary trait definition facilitated comparison of the results of this and previous studies [20, 35, 40, 48, 49]. 
Because of practical and economic reasons, health traits are currently not recorded in all mares presented for studbook inspection. Radiographic data were therefore not available for all studbook inspected mares, but only for those which were intended and preliminarily appointed for auction sale.

Compared to the total number of mares with available conformation data, the number of mares with complete records for conformation and radiography of their limbs was small $(\mathrm{n}=1422)$. Therefore, all radiographed horses and their contemporaries were considered for the correlation analyses. Included conformation data were all collected between 1995 and 2001. This procedure was supposed to ensure that results are not affected by possible effects of selection on conformation traits or modification of evaluation criteria. Scores on a subjective $0-10$ scale are traditionally used for evaluation of conformation and gaits in horses, and so they were during the whole study period.

In the genetic analyses, age at SBI evaluation was considered as a fixed effect because it explained a considerable part of the observed trait variance. Age-related significant decrease of the probability of mares to receive good scores for conformation and basic quality of gaits agrees with the literature $[2,4,5,16,19,27,29,48]$ and may be explained by different motivations to presenting young and older mares for studbook inspection. Genetic influences have been surmised previously and brought forward as an argument not to include age effect in the model for the genetic analyses [5]. However, dependence on genetic components was not seen in our data. Reasonable crossclassification of sires among age groups (results not shown) justified consideration of fixed age group effect in the genetic model for SBI traits.

A comparison of SBI scores and WH between radiographed mares with SBI data and all SBI evaluated contemporaries revealed significantly higher means in the radiographed mares (data not shown), indicating that conformation criteria played a relevant role in the pre-selection of horses for auction sale. Conversely, SBI presentation is not dependent on the radiological state of a mare. Accordingly, prevalences of OFF, OFH and DAH did not differ significantly between mares with SBI and radiographic data and all radiographed horses. Higher prevalences of navicular bone alterations in male than in female horses [37,40] accounted for significantly higher DNB prevalence and mean RNB score in all radiographed horses when compared to the radiographed and SBI evaluated mares.

Multivariate linear animal models were used for the estimation of genetic parameters for all traits. Given the available information on at least five categories, estimation bias of (co)variances due to violation of the assumption of normality should be minor with respect to conformation scores, WH and 
RNB [23]. However, four of the five considered radiographic findings were analyzed as all-or-none traits, resulting in extreme deviation from normality and prevalence dependent underestimation of heritabilities and residual correlations that had to be accounted for via transformation. Suitability of transformation factors $[6,43]$ had been substantiated previously via simulation [42], but heritabilities of less prevalent traits such as OFH and DAH might be overestimated. Genetic correlation estimates are not affected by transformation properties, but there is no way to correct for possible underestimation of additive genetic correlations between linear and binary traits [8].

Reported heritability estimates for a large variety of conformation traits differed little between different breeds of Warmblood horses and were very similar to our results $\left(\mathrm{h}^{2}=0.09-0.50\right.$ in this study $v s . \mathrm{h}^{2}=0.06-0.60$ in the literature; Appendix) [2, 4, 5, 7, 15, 16, 19, 25, 27, 29, 48]. The heritability estimate for withers height was higher in our data $\left(\mathrm{h}^{2}=0.49\right)$ than in the literature $\left(h^{2}=0.25-0.36\right)[5,15]$. Heritabilities of prevalences of radiographic findings agreed with those previously estimated in young Warmblood riding horses $[35,37,39,40,42]$.

There are very few investigations on genetic correlations between specific orthopedic diseases and conformation parameters. In previous genetic analyses in German Warmblood horses, the clinical terms osteochondrosis dissecans tarsi, bone spavin and podotrochlosis had been used instead of OFH, DAH and DNB or RNB, but traits were always defined radiologically $[48,49]$. Low prevalences and heritabilities interfere with reliable genetic correlation analyses, so that the validity of estimates of genetic correlations between weakly heritable radiographic findings $\left(\mathrm{h}^{2} \leq 0.07\right)$ and conformation data of relatives might be limited [49]. Generally higher heritabilities of RR traits and considerably larger amounts of available information with respect to both radiography and conformation data facilitated the detection of genetic correlations in this study when compared to previous studies (24 448 horses in this study, 456 and 3566 horses in previous animal model analyses) $[48,49]$, and reliability of estimated genetic correlations should exceed that of previous estimates. Absolute values of genetic correlations were always larger than, but in no case contradictory to those of corresponding phenotypic correlations (results not shown).

Genetic correlations between DAH and SBI traits were all negative. Previous authors also reported a significantly negative additive genetic correlation between radiographic signs of bone spavin and hind limb conformation $\left(r_{g}=-0.36\right)$ [49]. However, high standard errors of genetic correlation estimates involving DAH recommend cautious interpretation. Moderately negative additive genetic correlations were determined between OFF and front and 
hind limb conformation, between OFF and walk at hand and between DNB and hind limb conformation. Unfavorable conformation affects load distribution and the movement pattern of the respective horse and this way induces adjustments of weight bearing parts of the equine locomotory system. Constitutional irregularity of hind limb loading might directly relate to bony remodeling in hock joints [24,49], and indirectly to bony remodeling in front navicular bones. Development of biochemical heterogeneity and strength of articular cartilage is influenced by exercise and distribution of load in the particular joint [3], so that predilection sites for osteochondral fragmentation have been related to intra-articularly differing biomechanics and cartilage characteristics $[46,47]$. Our results support a relevant genetic correlation between unfavorable limb conformation and motion pattern and disposition of developing osseous fragments in metacarpo- and metatarsophalangeal joints. Previously surmised negative correlation between hock joint osteochondrosis and hind limb conformation [49] was neither phenotypically nor genetically seen in our data.

Both traits referring to the radiographic appearance of the navicular bones of the front limbs, i.e. DNB and RNB, showed a positive genetic correlation to the gait related SBI traits. An impressive and elaborate motion pattern, likely to be highly scored in SBI, may result in loading of the front navicular bones which induces radiologically visible adjustment. The navicular bone serves as a deflection plate for the deep digital flexor tendon. Every movement of the horse that involves flexion and extension of the distal limb affects the navicular bone and determines its bony structure. However, positive genetic correlation between navicular bone alterations and front limb conformation, previously reported in German Warmblood horses [49], was not found in this study.

Most distinct genetic and phenotypic correlations were positive and estimated between WH and the prevalences of OFF $\left(r_{g}=0.37-0.39\right)$ and OFH $\left(r_{g}=0.45-0.60\right)$. Moderately positive additive genetic correlation estimates agree with previous results $[20,31,32,43,49]$. The above-average definite size of a horse is often related to the above-average growth rate at a young age which might predispose to developmental orthopedic diseases such as osteochondrosis. However, the relationship between the prevalence of osteochondrosis or osteochondral fragmentation and nutrition parameters, which influence growth rate and daily weight gain of young horses, is not definitely clear yet $[9,14,45]$. OFF were genetically positively correlated to head and neck conformation. Higher proportions of horses with favorable scores for the head and neck among the large than among small horses may be responsible for these results. 
In this study radiographic findings in the limbs were considered, but significant negative genetic correlations between RR traits and limb conformation were only determined for OFF $\left(r_{g}=-0.19\right.$ to -0.30$)$ and DNB and RNB $\left(r_{g}=-0.15\right.$ to -0.20$)$. Negative genetic correlations between RR traits and gait related SBI traits were less clear than expected. Information on older horses may be needed to identify negative additive genetic correlations between radiographic findings and traits related to performance of riding horses [36]. Genetic correlations between RR traits and other SBI traits were in many cases low or not significantly different from zero (absolute value smaller than 0.20 ), often negative but sometimes positive. The results of the present study indicate that selection for a taller horse increases the risk of $\mathrm{OFF}$ and $\mathrm{OFH}$ and that the judgment of conformation of limbs can be useful for selection against OFF and DNB. Other traits are probably not very helpful for selection against radiographic findings in the limbs, so that the necessity of direct selection on the radiographic findings themselves remains. The reduction of prevalences of radiographic findings in the limbs is not only important because of their possible direct impact on the performance of riding horses. Maximum sales value will be achieved by radiologically sound horses because buyers often consider horses with radiological alterations to be at a higher risk to develop lameness problems [13]. Consistent selection for functional conformation might assist, but cannot replace breeding measures which are based on results of radiological examinations of horses. Despite antagonistic genetic correlations between individual radiographic findings $[35,37]$ it has been shown that appropriate breeding measures can concurrently lower the prevalences of the four quantitatively most important radiographic findings in the limbs of riding horses $[34,38]$. Combined use of conformation and radiological data will facilitate and accelerate selection progress with respect to the radiological health of the limbs of young Warmblood riding horses.

\section{REFERENCES}

[1] Axelsson M., Bjørnsdottir S., Eksell P., Håggstrøm J., Sigurðsson H., Carlsten J., Risk factors associated with hindlimb lameness and degenerative joint disease in the distal tarsus of Icelandic horses, Equine Vet. J. 33 (2001) 84-90.

[2] Bösch M., Reinecke S., Röhe R., Kalm E., Genetische Analyse von Merkmalen in der Reitpferdezucht - Varianzkomponenten für Merkmale der Fohlenbeurteilung, Stutbuchaufnahme (Exterieurbeurteilung) und Zuchtstutenprüfung, Züchtungskunde 72 (2000) 161-171.

[3] Brama P.A.J., TeKoppele J.M., Bank R.A., Barneveld A., Van Weeren P.R., Development of biochemical heterogeneity of articular cartilage: influences of age and exercise, Equine Vet. J. 34 (2002) 265-269. 
[4] von Butler-Wemken I., Duda J., Kaiser M., Genetische Analysen für Exterieurgesamtbeurteilungen und Beziehungen zu Körpermaßen bei Trakehner Stuten, Züchtungskunde 64 (1992) 92-100.

[5] Christmann L., Zuchtwertschätzung für Merkmale der Stutbuchaufnahme und der Stutenleistungsprüfung im Zuchtgebiet Hannover, Diss. agr., Georg-August Universität Göttingen, 1996.

[6] Dempster E.R., Lerner I.M., Heritability of threshold characters, Genetics 35 (1950) 212-235.

[7] Ducro B.J., Koenen E.P.C., Van Tartwijk J.M.F.M., Genetic correlation between movement and free-jumping traits and performance in show-jumping and dressage competition of Dutch Warmblood horses, 56th Annual Meeting of the EAAP, 5-8 June 2005, Uppsala, Sweden; H1.14.

[8] Gates P., Johansson K., Danell B., "Quasi-REML" correlation estimates between production and health traits in the presence of selection and confounding: a simulation study, J. Anim. Sci. 77 (1999) 558-568.

[9] Glade M.J., Belling T.H., A dietary etiology for osteochondrotic cartilage, J. Equine Vet. Sci. 6 (1986) 151-155.

[10] Haakenstad L.H., Chronic bone and joint diseases in relation to conformation in the horse, Equine Vet. J. 1 (1968) 248-260.

[11] Holmström M., Philipsson J., Relationship between conformation, performance and health of 4-year-old Swedish riding horses, Livest. Prod. Sci. 33 (1993) 293-312.

[12] Holmström M., Magnusson L.-E., Philipsson J., Variation in conformation of Swedish Warmblood horses and conformational characteristics of elite horses, Equine Vet. J. 22 (1990) 186-193.

[13] van Hoogmoed L.M., Snyder J.R., Thomas H.L., Harmon F.A., Retrospective evaluation of equine prepurchase examinations performed 1991-2000, Equine Vet. J. 35 (2003) 375-381.

[14] Jeffcott L.B., Savage C.J., Nutrition and the development of osteochondrosis (dyschondroplasia), Pferdeheilkunde 12 (1996) 338-342.

[15] Kaiser M., Duda J., von Butler-Wemken I., Genetische und nicht-genetische Einflüsse auf die Körpermaße einer Trakehner Zuchtpferdepopulation, Züchtungskunde 63 (1991) 335-341.

[16] Koenen E.P.C., Van Veldhuizen A.E., Brascamp E.W., Genetic parameters of linear scored conformation traits and their relation to dressage and show-jumping performance in the Dutch Warmblood riding horse population, Livest. Prod. Sci. 43 (1995) 85-94.

[17] Koenen E.P.C., Aldridge L.I., Philipsson J., An overview of breeding objectives for Warmblood sport horses, Livest. Prod. Sci. 88 (2004) 77-84.

[18] Kovac M., Groeneveld E., Garcia-Cortez A., VCE-5 User's Guide and Reference Manual Version 5.1.2., Institute for Animal Science and Animal Husbandry, Federal Agricultural Research Centre (Bundesforschungsanstalt für Landwirtschaft, FAL), Mariensee / Neustadt, Germany, 2003. 
[19] Kühl K., Preisinger K., Kalm E., Analyse von Leistungsprüfungen und Entwicklung eines Gesamtzuchtwertes für die Reitpferdezucht. 1. Mitteilung: Analyse der Exterieurbeurteilung und Leistungsprüfungen, Züchtungskunde 66 (1994) 1-13.

[20] KWPN (Koninklijke Vereiniging Warmbloed Paardenstamboek Nederland), The frequency and heredity of navicular disease, sesamoidosis, fetlock joint arthrosis, bone spavin, osteochondrosis of the hock: a radiographic progeny study, Koninklijke Vereniging Warmbloed Paardenstamboek Nederland (KWPN), Zeist, 1994.

[21] Magnusson L.-E., Studies on the conformation and related traits of Standardbred trotters in Sweden, Thesis, University of Agricultural Sciences SLU, Skara, 1985.

[22] Magnusson L.-E., Thafvelin B., Studies on the conformation and related traits of Standardbred trotters in Sweden, J. Anim. Breed. Genet. 1007 (1989) 135-148.

[23] Meijering A., Gianola D., Linear versus nonlinear methods of sire evaluation for categorical traits: a simulation study, Genet. Sel. Evol. 17 (1985) 115-132.

[24] Münzer B., Fries S., Hartung K., Röntgenuntersuchung der Sprunggelenke gesunder Fohlen. Ein Beitrag zur Spatdiagnostik, Tierärztl. Praxis 12 (1984) 211-216.

[25] Ohlsson L., Árnason L., Philips J., Quality evaluation of 4-year-old riding horses - a valuable performance indicator, Fakta. Husdjur 13 (1994) 4-8.

[26] Pool R.R., Meagher D.M., Stover S.M., Pathophysiology of navicular syndrome, Vet. Clin. North Am. Equine Pract. 5 (1989) 109-129.

[27] Preisinger R., Wilkens J., Kalm E., Estimation of genetic parameters and breeding values for conformation traits for foals and mares in the Trakehner population and their practical implications, Livest. Prod. Sci. 29 (1991) 77-86.

[28] Raker C.W., Clinical observations of bone and joint diseases in horses, Cornell Vet. (Suppl.) 58 (1968) 15-28.

[29] Reinecke S., Stand der Zuchtwertschätzung bei Stuten, II. Pferde-Workshop, Uelzen, 17-18. Februar 1998; 12-24.

[30] Rooney J.R., Bog spavin and tibiotarsal joint lesions in the horse, Mod. Vet. Pract. 54 (1973) 43-44.

[31] Sandgren B., Dalin G., Carlsten J., Osteochondrosis in the tarsocrural joint and osteochondral fragments in the fetlock joints in Standardbred trotters. I. Epidemiology, Equine Vet. J. Suppl. 16 (1993) 31-37.

[32] Sandgren B., Dalin G., Carlsten J., Lundeheim N., Development of osteochondrosis in the tarsocrural joint and osteochondral fragments in the fetlock joints of Standardbred totters. II. Body measurements and clinical findings, Equine Vet. J. Suppl. 16 (1993) 48-53.

[33] Schube S., Dämmrich K., Lauk H.D., Von Plocki K.A., Untersuchungen zur Pathogenese der Arthropathia deformans und der Entstehung von, "Chips" im Fesselgelenk der Pferde, Pferdeheilkunde 7 (1991) 69-77.

[34] Stock K.F., Distl O., Prediction of breeding values for osseous fragments in fetlock and hock joints, deforming arthropathy in hock joints and pathologic changes in the navicular bones of Hanoverian Warmblood horses, Livest. Prod. Sci. 92 (2005) 77-92. 
[35] Stock K.F., Distl O., Expected response to selection when accounting for orthopedic health traits in a population of Warmblood riding horses, Am. J. Vet. Res. 66 (2005) 1371-1379.

[36] Stock K.F., Distl O., Correlations between sport performance and different radiographic findings in the limbs of Hanoverian Warmblood horses, Anim. Sci. 82 (2006) 83-93.

[37] Stock K.F., Distl O., Genetic analyses of radiographic appearance of the navicular bones in the Warmblood horse, Am. J. Vet. Res. 67 (2006) 1013-1019.

[38] Stock K.F., Distl O., Genetic correlations between osseous fragments in fetlock and hock joints, deforming arthropathy in hock joints and pathologic changes in the navicular bones of Warmblood riding horses, Livest. Sci. (2006) (available online, doi:10.1016/j.livsci.2006.04.027).

[39] Stock K.F., Hamann H., Distl O., Variance component estimation on the frequency of deforming arthropathies in limb joints of Hanoverian Warmblood horses, J. Anim. Breed. Genet. 121 (2004) 269-288.

[40] Stock K.F., Hamann H., Distl O., Variance component estimation on the frequency of pathologic changes in the navicular bones of Hanoverian Warmblood horses, J. Anim. Breed. Genet. 121 (2004) 289-301.

[41] Stock K.F., Hamann H., Distl O., Factors associated with the prevalence of osseous fragments in limb joints of Hanoverian Warmblood horses, Vet. J. 171 (2006) 147-156 (online since November 2004, doi:10.1016/j.tvj1.2004.09.007).

[42] Stock K.F., Hamann H., Distl O., Estimation of genetic parameters for the prevalence of osseous fragments in limb joints of Hanoverian Warmblood horses, J. Anim. Breed. Genet. 122 (2005) 271-280.

[43] Vinson W.E., White J.M., Kliewer R.H., Overall classification as a selection criterion for improving categorically scored components of type in Holsteins, J. Dairy Sci. 59 (1976) 2104-2114.

[44] Wallin L., Strandberg E., Philipsson J., Phenotypic relationship between test results of Swedish Warmblood horses as 4-year-old and longevity, Livest. Prod. Sci. 68 (2001) 97-105.

[45] van Weeren P.R., Sloet van Oldruitenborgh-Osterbaan M.M., Barneveld A., The influence of birth weight, rate of weight gain and final achieved height and sex on the development of osteochondrotic lesions in a population of genetically predisposed Warmblood foals, Equine Vet. J. Suppl. 31 (1999) 26-30.

[46] van Weeren P.R., Equine osteochondrosis: a challenging enigma, Pferdeheilkunde 21 (2005) 285-292.

[47] van Weeren P.R., Barneveld A., The effect of exercise on the distribution and manifestation of osteochondrotic lesions in the Warmblood foal, Equine Vet. J. Suppl. 31 (1999) 16-25.

[48] Willms F., Röhe R., Kalm E., Genetische Analyse von Merkmalskomplexen in der Reitpferdezucht unter Berücksichtigung von Gliedmaßenveränderungen. 2. Mitteilung: Genetische Beziehungen zwischen Merkmalen aus der Stutbucheintragung, Stutenleistungsprüfung und Gliedmaßenveränderungen, Züchtungskunde 71 (1999) 346-358.

[49] Winter D., Bruns E., Glodek P., Hertsch B., Genetische Disposition von Gliedmaßenerkrankungen bei Reitpferden, Züchtungskunde 68 (1996) 92-108. 
Appendix. Reported heritabilities of conformation traits evaluated in different breeds of riding horses.

\begin{tabular}{|c|c|c|c|}
\hline Trait & Breed & $\mathrm{h}^{2}$ & Reference \\
\hline Type & GWB & $0.28-0.42$ & {$[2,4,5,19,27,29,48]$} \\
\hline General impression and development & GWB & $0.25-0.35$ & {$[4,5]$} \\
\hline Frame & GWB & 0.23 & {$[5]$} \\
\hline Head & GWB & 0.42 & [5] \\
\hline \multirow{2}{*}{$\begin{array}{l}\text { Neck (head-neck connection, length, position and muscularity } \\
\text { of neck) }\end{array}$} & GWB & 0.25 & {$[5]$} \\
\hline & DWB & $0.12-0.21$ & [16] \\
\hline \multirow[t]{3}{*}{ Total conformation (body shape) } & GWB & $0.17-0.28$ & {$[4,5,27]$} \\
\hline & SWB & $0.29-0.33$ & {$[25,46]$} \\
\hline & DWB & 0.33 & {$[7]$} \\
\hline \multirow[t]{2}{*}{ Front limbs } & GWB & $0.06-0.16$ & {$[2,5,19,29,48]$} \\
\hline & DWB & 0.17 & [16] \\
\hline Shoulder (length and position / slope of shoulder) & DWB & $0.16-0.17$ & {$[16]$} \\
\hline \multirow[t]{2}{*}{ Hind limbs } & GWB & $0.10-0.29$ & {$[2,5,19,29,48]$} \\
\hline & DWB & 0.23 & {$[16]$} \\
\hline Correctness of legs (quality and substance of legs) & DWB & $0.18-0.19$ & {$[16]$} \\
\hline Correctness of feet (stance of pastern, hoof form, heels) & DWB & $0.09-0.21$ & {$[16]$} \\
\hline \multirow[t]{2}{*}{ Back line (length and shape of back and loins) } & GWB & $0.16-0.25$ & {$[2,19,29,48]$} \\
\hline & DWB & $0.16-0.18$ & {$[16]$} \\
\hline \multirow[t]{2}{*}{ Withers (height and length of withers) and saddle bearing area } & GWB & 0.35 & {$[5]$} \\
\hline & DWB & $0.19-0.20$ & [16] \\
\hline Croup (length and formation of croup, muscularity of haunches) & DWB & $0.15-0.28$ & {$[16]$} \\
\hline Depth of the body & GWB & $0.14-0.15$ & {$[19,48]$} \\
\hline \multirow[t]{2}{*}{ Gaits (correctness and balance of gaits) } & GWB & $0.12-0.28$ & {$[2,4,5,19,27,29,48]$} \\
\hline & SWB & $0.34-0.35$ & {$[7,25]$} \\
\hline \multirow{2}{*}{$\begin{array}{l}\text { Walk at hand (stride length, elasticity and correctness of walk; } \\
\text { at hand and/or free) }\end{array}$} & GWB & 0.19 & {$[5]$} \\
\hline & DWB & $0.12-0.25$ & {$[7,16]$} \\
\hline \multirow{2}{*}{$\begin{array}{l}\text { Impetus and elasticity (stride length, elasticity, impulsion, car- } \\
\text { riage and correctness of trot; trot at hand and/or free) }\end{array}$} & GWB & $0.19-0.39$ & {$[2,5,19,27,29,48]$} \\
\hline & DWB & $0.20-0.32$ & {$[7,16]$} \\
\hline Withers height & GWB & $0.25-0.36$ & {$[5,15]$} \\
\hline
\end{tabular}

Referenced studies: reference, investigated population, occasion of conformation evaluation; mode of analysis.

[2] 16523 Holstein WB mares (mean 4.7 y.), SBI 1972-1998; LAM (REML).

[4] 2300 Trakehner mares (mean 4 y.), SBI 1979-1987; LSM (REML).

[5] 5347 Hanoverian WB mares (3-6 y.; MPT 1987-1993), SBI 1984-1993; LAM (REML).

[7] 36159 Dutch WB horses (2-13 y.), SBI 1992-2002; LAM (REML).

[15] 6913 Trakehner horses (6511 9, 402 ơ ; 3-4 y.), SBI 1950-1987; LSM (REML).

[16] 10665 Dutch WB mares (3-7 y.), SBI 1989-1993; LAM (REML).

[19] 6062 Holstein WB mares (mostly 3 y.), SBI 1982-1987; LSM (LSML).

[25] 3601 Swedish WB horses (mean 4 y.), RHQT 1968-1982.

[27] 4226 Trakehner mares (no age specification), SBI 1981-1989; LSM (REML).

[29] 15639 Holstein WB mares (no age specification), SBI 1972-1997; LSM (LSML).

[44] 3708 Swedish WB horses (1614 9, 2094 ơ; 4-5 y.), RHQT 1973-1986; LAM (REML).

[48] 10300 Holstein WB mares (no age specification), SBI 1978-1994; LAM (GS).

WB: Warmblood; GWB (DWB, SWB): German (Dutch, Swedish) Warmblood; y: years of age; SBI: studbook inspection;

MPT: mare performance test (1 day field test or stationary test of 19 days duration); RHQT: riding horse quality test (1 day field test); LAM: linear animal model; LSM: linear sire model; REML: residual maximum likelihood; LSML: least square maximum likelihood; GS: Gibbs sampling. 
Online Materials 
Supplementary table. Mean scores and ranges of scores on a scale from 0 (not shown) to 10 (excellently shown) of conformation traits and means and ranges of height at withers in 20768 mares evaluated on the occasion of studbook inspection (SBI) of the Hanoverian Warmblood in 1995-2004 and in the 1422 SBI evaluated mares with radiographic data.

\begin{tabular}{|c|c|c|}
\hline Trait & $\begin{array}{l}\text { Mares with SBI } \\
\text { records } \\
(\mathrm{n}=20768)\end{array}$ & $\begin{array}{l}\text { Mares with SBI and } \\
\text { radiography records } \\
\quad(\mathrm{n}=1422)\end{array}$ \\
\hline Type & $\begin{array}{c}7.32 \pm 0.67 \\
(5-10)\end{array}$ & $\begin{array}{c}7.06 \pm 0.72 \\
(4-10)\end{array}$ \\
\hline Head & $\begin{array}{c}7.38 \pm 0.81 \\
(5-10)\end{array}$ & $\begin{array}{c}7.23 \pm 0.83 \\
(4-10)\end{array}$ \\
\hline Neck & $\begin{array}{c}7.20 \pm 0.74 \\
(5-10)\end{array}$ & $\begin{array}{c}7.01 \pm 0.76 \\
(3-10)\end{array}$ \\
\hline Saddle bearing area & $\begin{array}{c}7.17 \pm 0.68 \\
(4-10)\end{array}$ & $\begin{array}{c}7.00 \pm 0.72 \\
(4-10)\end{array}$ \\
\hline Frame & $\begin{array}{l}7.04 \pm 0.73 \\
\quad(5-9)\end{array}$ & $\begin{array}{l}6.79 \pm 0.76 \\
\quad(3-9)\end{array}$ \\
\hline Total conformation & $\begin{array}{l}7.03 \pm 0.57 \\
\quad(5-9)\end{array}$ & $\begin{array}{l}6.78 \pm 0.68 \\
\quad(4-9)\end{array}$ \\
\hline Front limb conformation & $\begin{array}{l}6.79 \pm 0.72 \\
\quad(4-9)\end{array}$ & $\begin{array}{l}6.62 \pm 0.74 \\
\quad(3-9)\end{array}$ \\
\hline Hind limb conformation & $\begin{array}{l}6.53 \pm 0.72 \\
\quad(4-9)\end{array}$ & $\begin{array}{c}6.35 \pm 0.76 \\
\quad(3-9)\end{array}$ \\
\hline General impression and development & $\begin{array}{c}7.11 \pm 0.60 \\
\quad(4-9)\end{array}$ & $\begin{array}{c}6.81 \pm 0.69 \\
(4-10)\end{array}$ \\
\hline Correctness of gaits & $\begin{array}{l}6.86 \pm 0.71 \\
\quad(5-9)\end{array}$ & $\begin{array}{c}6.69 \pm 0.73 \\
(4-9)\end{array}$ \\
\hline Walk at hand & $\begin{array}{c}7.09 \pm 0.88 \\
(5-10)\end{array}$ & $\begin{array}{l}6.84 \pm 0.90 \\
\quad(4-10)\end{array}$ \\
\hline Impetus and elasticity & $\begin{array}{c}7.36 \pm 0.82 \\
(5-10)\end{array}$ & $\begin{array}{c}6.93 \pm 0.87 \\
(3-10)\end{array}$ \\
\hline Total score & $\begin{array}{c}7.15 \pm 0.55 \\
(5-9)\end{array}$ & $\begin{array}{c}6.87 \pm 0.64 \\
(4-9)\end{array}$ \\
\hline Height at withers & $\begin{array}{c}165.94 \pm 2.84 \\
(150-177)\end{array}$ & $\begin{array}{c}165.44 \pm 3.02 \\
(143-185)\end{array}$ \\
\hline
\end{tabular}

